\title{
Effects of aquatic exercise on depression and anxiety in ischemic stroke subjects
} \author{
Ricardo Jacó de Oliveira ${ }^{4}$ \\ ${ }^{1} 5^{\text {th }}$ Military State Fireman, Uberlândia, Brazil \\ ${ }^{2}$ University of Trás-os-Montes and Alto Douro-UTAD/CIDESD, Vila Real, Portugal; \\ *Corresponding Author: ngarrido@utad.pt \\ ${ }^{3}$ University of Beira Interior-UBI/CIDESD, Covilhã, Portugal \\ ${ }^{4}$ University of Brasília-UnB, Brasília, Brazil
}

Felipe J. Aidar ${ }^{1}$, Nuno D. Garrido ${ }^{2}$, António J. Silva ${ }^{2}$, Victor M. Reis ${ }^{2}$, Daniel A. Marinho ${ }^{3}$,

Received 6 December 2012; revised 5 January 2013; accepted 13 January 2013

\section{ABSTRACT}

Background: Stroke ranks third and is the leading cause of permanent disability in western countries. Furthermore there are no treatments for the psychosocial effects of this pathology. Purpose: Analyse the effect of an aquatic exercise program in depression and trace and state anxiety in subjects who suffered an ischemic stroke. Methods: Two groups were analyzed: experimental group (EG) $n=15,50.3 \pm 9.1$ years; control group (CG) $n=13,52.5 \pm 7.7$ years. EG underwent a 12-week aquatic exercise program. Both groups were evaluated in pre- and posttreatment using Beck Depression Inventory (BDI) and Trace State Anxiety Inventory (IDATE). Wilcoxon signed-rank and Mann-Whitney tests were used to compare moments and groups, respectively. Results: The BDI scores of aquatic activities were: pre-treatment, $17.4 \pm 7.7$ and $16.9 \pm$ 8.6 for the EG and CG, respectively; post-treatment, $13.2+7.1$ and $16.4+7.9$ for the EG and CG, respectively. The IDATE scores for anxiety trace in strength training were: pre-treatment, $43.2+$ 12.5 and $42.9+12.2$ for the EG and CG, respectively; post-treatment, $39.7+7.1$ and $42.6+12.1$ for the EG and CG, respectively. The IDATE scores for anxiety state in strength training were: pre-treatment, $46.9+7.6$ and $47.4+8.1$ for the EG and CG, respectively; post-treatment, $44.4+$ 7.9 and $47.5+8.0$ for the EG and CG, respectively. Significant differences were found in pre and post-treatment values in the EG and between groups in the depression and trace and state anxiety levels in post-treatment $(p<0.05)$. Conclusions: Aquatic physical activity contributes to an improvement of the levels of depression and anxiety in people who suffered a stroke.
Keywords: Aquatic Physical Activity; Beck

Depression Inventory; Cardiovascular Disease; Cerebrovascular Accident; Ischemic Stroke; Trace

State Anxiety Inventory

\section{INTRODUCTION}

The stroke incidence has increased in recent years. Regarding its mortality, the stroke ranks third in causes of permanent disability, being the main cause of permanent disability in western countries [1,2]. The American Heart Association estimates that there are four million stroke survivors in the United States and that 600.000 new cases occur annually [3]. In Brazil stroke represents one third of deaths from circulatory diseases per year and assumes a prominent place in conjunction with other cardiovascular problems $[4,5]$.

Moreover, treatments for possible negative psychosocial effects of the disease are uncertain and somewhat unreliable [6], being the most appropriate treatment directed towards its systematization with accurate diagnosis. Moreover, action within an optimal timeframe, within the first three hours after the stroke and with the proper workup, is also reported [7-11]. In this sense, one can observe a clear tendency to treatments only directed for pharmacologic intervention. In the same way, a delayed intervention tends to cause more squeals and treatment difficulties [12]. Indeed, the squeals may occur as a consequence of cerebral ischemia lasting four to six hours, producing irreversible neurological damage [13, 14]. Moreover, among adults, the stroke squeals are considered the most common causes of disability [15]. Accordingly, there is a need to continued treatment and monitoring of people with stroke squeals [16], where the psychosocial aspects tend to be compromised.

On the other hand, stroke is associated to cognitive dysfunction and functional impairment, leading to diffi- 
culties in walking and interference in aspects related to depression and social features [17]. Thus, the presence of depression and anxiety should be appropriately treated, where the focus of intervention should be to improve functional aspects [18].

Physical activity can have positive effects on physical and psychosocial aspects. The practice of moderate physical activity is likely to have a positive impact, significantly reducing anxiety levels [19], suggesting that the anxiolytic effects of acute exercise tend to be statistically positive [20]. Similarly, strength training besides promoting strength gains also significantly reduces anxiety levels in stroke survivors [21]. Moreover, Ischemic stroke survivors undergoing the practice of aquatic activities showed significant improvements in levels of quality of life when compared to survivors who were not submitted to physical activities [6].

Apart from this, the benefits of physical activity for people affected by stroke has been reported and linked to improvements in standards of life quality [22], and related to rehabilitation of these patients [23].

Nevertheless, few studies have evaluated the improvement in depression and anxiety in stroke patients through aquatic physical activities.

Thus, the aim of this study was to assess the influence of aquatic exercise on depression and anxiety in persons with squeals due to ischemic stroke. We hypothesized that aquatic exercise decrease depression and anxiety in persons with squeals due to ischemic stroke.

\section{METHODS}

\subsection{Sample}

Thirty one subjects participated in this study and were randomly divided, 16 to the Experimental Group (EG) and 15 to the Control Group (CG). These groups were changed after the beginning of activities as one of the EG subjects did not follow the program. In the CG two subjects were not evaluated in post-treatment. Finally, the EG was composed of 15 subjects, being 10 males and 5 females (and CG was composed of 13 individuals, being 9 males and 4 females). Groups' characteristic is shown in Table 1.

The participation in the study required previous medical clearance. As a criterion for eligibility, only subjects who have suffered ischemic stroke for at least one year and subjects having hemiplegia or hemiparesis. The classification was followed according to the Ranking Scale [24,25]. In GE $6.7 \%$ of the subjects had mild disability, $66.7 \%$ moderate disability and $26.7 \%$ higher disability. In CG $15.4 \%$ of the subjects had mild disability, $61.5 \%$ moderate disability and $23.1 \%$ higher disability (Table 2). There were neither asymptomatic patients nor patients
Table 1. Groups data.

\begin{tabular}{cc}
\hline Experimental group $(\mathrm{n}=15)$ & Mean and SD \\
\hline age & $50.3 \pm 9.1$ \\
age (male) & $50 \pm 10.6$ \\
age (female) & $50.8 \pm 7.6$ \\
sex (male/female) & $10 / 5$ \\
Control group $\mathrm{n}=(13)$ & Mean and SD \\
age & $52.5 \pm 7.7$ \\
age (male) & $52.3 \pm 9.0$ \\
age (female) & $52.8 \pm 4.8$ \\
sex (male/female) & $9 / 4$ \\
\hline
\end{tabular}

Table 2. Deficit and affected side in relation to dominant and non-dominant limb.

\begin{tabular}{|c|c|c|}
\hline \multirow[t]{2}{*}{ Experimental group ${ }^{*}$} & \multicolumn{2}{|c|}{ No subjects } \\
\hline & Dominant & Non-dominant \\
\hline Mild disability & 0 & 1 \\
\hline Moderate disability & 1 & 9 \\
\hline Higher disability & 1 & 3 \\
\hline \multicolumn{3}{|l|}{ Control group ${ }^{*}$} \\
\hline Mild disability & 1 & 1 \\
\hline Moderate disability & 2 & 6 \\
\hline Higher disability & 0 & 3 \\
\hline
\end{tabular}

*All subjects were right-handed.

with non-disabling deficit or with severe disabilities.

All subjects, after being informed about the procedures, voluntarily agreed to participate in this study, and signed a written consent to resolution 196/1996 of the National Health Council, in accordance with the ethical principles contained in the Declaration of Helsinki (1964, revised in 1975, 1983, 1989, 1996 and 2000), of the World Medical Association.

The subjects underwent a pre-treatment testing and the experimental group (EG) began aquatic physical activities while the other group (CG) only began the activities four months after the EG, thus serving as control group.

\subsection{Instruments}

\subsubsection{Beck Depression Inventory}

The Beck Depression Inventory (Beck Depression Inventory-BDI) [26,27] has been often used as a measure of self-assessment of depression in research and clinical practice [28], as it is validated in several countries.

The original scale consists of 21 items, including symptoms and attitudes, whose measurement ranges from 0 to 3 . These items are relate to sadness, pessimism, sense of failure, lack of satisfaction, feelings of guilt, feelings of punishment, self-deprecation, self-accusations, suici- 
dal ideas, crying spells, irritability, social withdrawal, indecisiveness, body image distortion, work inhibition, sleep disturbance, fatigue, loss of appetite, weight loss, somatic concerns and decreased libido.

The Beck Inventory [26,27,29,30] allows various cutoffs points, depending on the nature of the sample and the study objectives. For the proposed sample "Center for Cognitive Therapy" [31] recommends the following cutoffs points: $<10=$ no depression or minimal depression; 10 to 18 = from mild to moderate depression; 19 to $29=$ moderate to severe depression; 30 to $63=$ severe depression.

\subsubsection{Trace State Anxiety Inventory IDATE (State-Trait Anxiety Inventory-STAI: Form Y)}

For the assessment of anxiety the Trace State Anxiety Inventory (IDATE) [32,33] was used. The IDATE is a self-assessment questionnaire divided in two parts: the first assesses anxiety trait-IDATE I (referring to aspects of personality) and the second part assesses the anxiety state-IDATE II (referring to the systemic aspects of the context). Each of these parts consists of 20 statements. A score ranging from 1 to 4 is assigned to each item of both scales and the total score can range from 20 (minimum) to 80 (maximum). When answering the questionnaire, the subject should consider that STATE means "as the subject feels at that particular moment" and TRACE "as the subject generally feels itself'. Usually the scores may indicate a low degree of anxiety $(0-30)$, medium degree of anxiety (31 - 49) and high degree of anxiety (>50), i.e., the lower the score, the lower the degree of anxiety $[32,33]$.

\subsection{Procedures}

Questionnaires were administered before the beginning of physical activity programs (pre-treatment) and then after 12 weeks (post-treatment). Between pretreatment and post-treatment EG underwent an aquatic physical activity program and the CG was not submitted to any kind of specific physical activity.

Aquatic activities took place in a swimming pool with $25 \times 12.5 \mathrm{~m}$ size and with an average depth of $1.5 \mathrm{~m}$. Several apparatus for the practice of water activities were used during aquatic exercises. Activities were undertaken twice a week in sessions lasting between 45 and 60 minutes in the period from 07:00 to 19:00 hours. The sessions comprised 5 to 10 minute of dry land warm up activities; 5 to 10 minutes of walking in the swimming pool with breast level water height; 5 to 10 minutes pedaling work out with Spaghetti; 5 to 10 minutes of climbing and descending of pool degrees; 5 to 10 minutes of exercises for upper and lower limbs with educational material; breathing exercises, doing bubbles in the water; $10 \mathrm{~min}$ utes of swimming; and 5 minutes of low-intensity exercise allowing calm return.

The Borg Scale of perceived exertion was used, at levels comprised between 12 and 17 points [34]. The scale was presented to the subjects at the beginning of the activities. Subjects need to attribute a numerical value corresponding to their perception of effort at that particular moment. These values were corrected till the intended values and were readjusted during the intervention.

\subsection{Statistics}

Normality was determined by Shapiro-Wilk test. Since the very low value of the $\mathrm{N}($ i.e., $\mathrm{N}<30$ ) and the rejection of the null hypothesis (H0) in the normality assessment, non-parametric procedures were adopted. Mean \pm 1 standard deviation was determined for each variable. Changes between pre and post-treatment were verified by the Wilcoxon test for repeated measures. To compare EG with the CG in pre and post-treatment the MannWhitney test for independent samples was used. All statistical procedures were conducted with SPSS software (v. 13.0, Apache Software Foundation, Chicago, IL, USA). The level of significance was set at $p<0.05$.

\section{RESULTS}

Subjects were evaluated before and after the onset of exercise (pre and post-treatment), establishing comparative data to understand the effects that the activities provided for depression and anxiety (Table 3).

The results showed a significant difference for the EG in the variables analysed (depression, anxiety trace and anxiety state). No significant difference was found between pre and post-treatment for the CG $(p \leq 0.05)$. In the comparison between the EG and CG significant differences were found $(p \leq 0.05)$ for indicators of depression and anxiety in the post-treatment (Table 4). The results pointed towards significant differences $(p \leq 0.05)$ between the EG and $\mathrm{CG}$ on levels of depression and anxiety trait and state. No differences were obtained between EG and CG in pre-test.

\section{DISCUSSION}

The aim of this study was to assess the influence of aquatic exercise on depression and anxiety in persons with sequelae due to ischemic stroke. Main results suggested that the levels of depression and anxiety in people who suffered a stroke have decreased when involved in an aquatic activity program during 12 weeks.

The results show that the subjects had similar levels of depression in the pre-test and were considered moderately depressed. The results corroborate other studies that indicate that stroke is a severe disease, with high morta- 
Table 3. Means $( \pm \mathrm{SD})$ in pre and post-treatment concerning depression using the Beck depression inventory (depression) and IDATE I and II (Anxiety trace and state) in experimental group (EG) and control group (CG).

\begin{tabular}{lcc}
\hline & Pre-Test & Post-Test \\
\hline EG-aquatic activities (depression) & $17.4 \pm 7.7$ & $13.2 \pm 7.1^{*}$ \\
CG (depression) & $16.9 \pm 8.6$ & $16.4 \pm 7.9$ \\
EG—-strength training (anxiety trace) & $43.2 \pm 12.5$ & $39.7 \pm 7.1^{*}$ \\
CG (anxiety trace) & $42.9 \pm 12.2$ & $42.6 \pm 12.1$ \\
EG-strength training (anxiety state) & $46.9 \pm 7.6$ & $44.4 \pm 7.9^{*}$ \\
CG (anxiety state) & $47.4 \pm 8.1$ & $47.5 \pm 8.0$ \\
\hline
\end{tabular}

${ }^{*} \mathrm{p} \leq 0.05$ (Wilcoxon test).

Table 4. Comparison of means $( \pm \mathrm{SD})$ of depression using the Beck depression inventory and anxiety using the IDATE I and II in EG and CG in post treatment.

\begin{tabular}{lcc}
\hline & EG & CG \\
\hline Depression & $13.2 \pm 7.1^{*}$ & $16.4 \pm 7.9$ \\
Anxiety trace & $39.7 \pm 7.1^{*}$ & $42.6 \pm 12.1$ \\
Anxiety state & $44.4 \pm 7.9^{*}$ & $47.5 \pm 8.0$ \\
\hline
\end{tabular}

${ }^{*} \mathrm{p} \leq 0.05$ (Mann-Whitney test).

lity and high rates of recidivism [35-39], showing that sequels tend to be definitive [40-42]. The same type of results could be expected if the subjects had used drugs for this purpose. However, there was no pharmacological support, which can be considered as a positive result. In the study of Simis and Nitrini [43], where pharmacological support was used, after three months of follow up, patients who initially had mild depressive symptoms began to have higher values, where treatment was associated with improved mood, memory and attention.

A prospective study with 3525 subjects, aged between 65 and 84 years, in several Italian cities, showed that older people tend to an increased risk of depression caused mainly by declining physical condition [44], thus corroborating the results of this study where inactive people tend to have an increased rate of depression. In contrast, a study that examined 9374 patients who underwent surgery in 69 hospitals in North America, has shown that depression is not only associated with a relatively active life, but to other associated factors [45]. Similarly, in a study that evaluated 101 patients, with chronic symptomatic disease at neuromuscular level, it was observed the relationship of physical dysfunction with depression and anxiety. Two years after the diagnosis, these patients had increased the levels of depression that could be associated with different types of dysfunctions in relation to pathology [46], converging with our results, where inactivity could cause an increase in depression levels.

Yet, research has shown that symptoms of depression and disability are closely related, when studying moderate physical activities and the association between signs of depression and disability, with 645 subjects aged 65 years or more [47]. Physical activity had a modifier effect in symptoms of depression and proved to be a factor of change on disability matters. Even moderate and intense physical activity lead to a significant decrease in symptoms of depression, assuming that physical activities are an effective means to reduce the signs of depression [47]. Therefore, regular exercise tends to improve the quality of life, the ability to work and leisure, and reduces the incidence of new strokes and the consequent decrease in physical ability [48]. The evidence point out that physical activity is the best way to reduce stress in people with disabilities and a tendency for improvements in social and emotional aspects for those who practice it regularly [49]. In a research conducted in Brazil, depression following stroke was analyzed, noting that this long-term psychosocial status proved to be very important in victims of cerebrovascular events [50]. When trying to identify what caused the maintenance of high levels of depression, it was pointed out that depression was significantly higher in women and it was associated with work issues, educational level, low social activity, functional cognitive problems and dependence on someone else, and still the prevalence of other pathologies associated with the stroke [50]. For anxiety, the results suggest that aquatic physical activities were an important factor in reducing anxiety levels. Corroborating with this, in a study involving 104 patients, the levels of anxiety and depression after stroke were compared four months after the event, where $23 \%$ of subjects presented high levels of anxiety and 19\% presented high levels of depression, where anxiety levels remained high even after four months after the stroke [51]. These results are similar to the results in our study in the control group, which even after three months of the stroke subjects showed no improvement in anxiety levels. In an investigation where 71 patients with confirmed history of stroke were studied, it was demonstrated that the absence of movement could increase levels of anxiety [52], indicating that immobilizing patients after stroke, tends to increase the negative aspects of the pathology and further contributes to worsen the symptoms of anxiety and irritability. Fure [53] reported that in patients affected by stroke in Norway, the emotional factor may be neglected after an event and that anxiety exceeds normal levels in $20 \%-30 \%$ of patients. Yet $10 \%-15 \%$ of patients had an emotional imbalance, and $50 \%-70 \%$ of patients had reduction of initiatives and increased fatigue, and that the treatment was only pharmacological, with no evidence of the success of medical intervention. On the other hand, the beneficial effects of exercise are well documented, but physical activity can increase levels of anxiety as well. In assessing 
the relationship of physical activity and anxiety in 3289 subjects, Conn [54] noted that some activities could reduce anxiety in healthy adults; however, there could be a direct relationship between casual increased anxiety and physical activities.

The intervention of this study was to simulate what was preconized by Subirats Bayego et al. [55], where the benefits of physical activity tend to encompass stroke among other diseases, being the benefits associated with moderate aerobic exercise for at least 30 minutes, 5 days a week or vigorous exercise for at least 20 minutes 3 days a week.

\section{CONCLUSION}

The results of this study suggest that the practice of aquatic physical activity tends to promote improvements in the levels of depression and anxiety in people who suffered an Ischemic Stroke.

\section{REFERENCES}

[1] Kjeldsen, S.E., Erdine, S., Farsang, C., Sleight, P. and Mancia, G. (2002) 1999 WHO/ISH Hypertension Guidelines-Highlights \& ESH update. Journal of Hypertension, 20, 153-155. doi:10.1097/00004872-200201000-00022

[2] Frey, J.L., Jahnke, H.K. and Bulfinch, E.W. (1998) Differences in stroke between white, hispanic, and native American patients: The barrow neurological institute stroke database. Stroke; A Journal of Cerebral Circulation, 29, 29-33. doi:10.1161/01.STR.29.1.29

[3] Haacke, C., Althaus, A., Spottke, A., Siebert, U., Back, T. and Dodel, R. (2006) Long-term outcome after stroke: Evaluating health-related quality of life using utility measurements. Stroke; A Journal of Cerebral Circulation, 37, 193-198. doi:10.1161/01.STR.0000196990.69412.fb

[4] Pittella, J.E.H. and Duarte, J.E. (2002) Prevalence and pattern of distribution of cerebrovascular diseases in 242 hospitalized elderly patients, in a general hospital, autopsied in Belo Horizonte, Minas Gerais, Brazil, from 1976 to 1997. Arquivos De Neuro-Psiquiatria, 60, 47-55. doi:10.1590/S0004-282X2002000100010

[5] Rezende, E.M., Sampaio, I.B.M. and Ishitani, L.H. (2004) Multiple causes of death due to non-communicable diseases: A multidimensional analysis. Cadernos De Saúde Pública/Ministério Da Saúde, Fundação Oswaldo Cruz, Escola Nacional De Saúde Pública, 20, 1223-1231. doi:10.1590/S0102-311X2004000500016

[6] Aidar, F.J., Silva, A.J., Reis, V.M., Carneiro, A. and Carneiro-Cotta, S. (2007) A study on the quality of life in ischaemic vascular accidents and its relation to physical activity. Revista De Neurologia, 45, 518-522.

[7] Solenski, N.J. (2004) Transient ischemic attacks: Part I. Diagnosis and evaluation. American Family Physician, 69, 1665-1674.

[8] Esteve, M., Serra-Prat, M., Zaldívar, C., Verdaguer, A. and Berenguer, J. (2004) Impact of a clinical pathway for stroke patients. Gaceta Sanitaria/S.E.S.P.A.S, 18, 197-204.

[9] Maestre-Moreno, J.F. (2006) Stroke and resources for urgent neurological attention: Why arrive in time? Revista De Neurologia, 42, 65-67.

[10] Morales-Ortiz, A., Amorín, M., Fages, E.M., et al. (2006) Use of extra-hospital emergency systems in the treatment of acute stroke in the region of Murcia. Possible repercussions on the urgent care of stroke patients. Revista De Neurologia, 42, 68-72.

[11] Chang, C.-F., Lin, S.-Z., Chiang, Y.-H., Morales, M., Chou, J., Lein, P., Chen, H.-L., Hoffer, B.J. and Wang, Y. (2003) Intravenous administration of bone morphogenetic protein-7 after ischemia improves motor function in stroke rats. Stroke; A Journal of Cerebral Circulation, 34, 558564. doi:10.1161/01.STR.0000051507.64423.00

[12] Mokudai, T., Ayoub, I.A., Sakakibara, Y., Lee, E.J., Ogilvy, C.S. and Maynard, K.I. (2000) Delayed treatment with nicotinamide (Vitamin B(3)) improves neurological outcome and reduces infarct volume after transient focal cerebral ischemia in Wistar rats. Stroke; A Journal of Cerebral Circulation, 31, 1679-1685.

doi:10.1161/01.STR.31.7.1679

[13] Chang, K.-C., Tseng, M.-C. and Tan, T.-Y. (2004) Prehospital delay after acute stroke in Kaohsiung, Taiwan. Stroke; A Journal of Cerebral Circulation, 35, 700-704. doi:10.1161/01.STR.0000117236.90827.17

[14] Abboud, H., Labreuche, J., Plouin, F. and Amarenco, P. (2006) High blood pressure in early acute stroke: A sign of a poor outcome? Journal of Hypertension, 24, 381386. doi:10.1097/01.hjh.0000200516.33194.e3

[15] Samsa, G.P. and Matchar, D.B. (2004) How strong is the relationship between functional status and quality of life among persons with stroke? Journal of Rehabilitation Research and Development, 41, 279-282. doi:10.1682/JRRD.2003.08.0117

[16] Clark, T.G., Murphy, M.F.G. and Rothwell, P.M. (2003) Long term risks of stroke, myocardial infarction, and vascular death in "low risk" patients with a non-recent transient ischaemic attack. Journal of Neurology, Neurosurgery, and Psychiatry, 74, 577-580. doi:10.1136/jnnp.74.5.577

[17] Moon, Y.-S., Kim, S.-J., Kim, H.-C., Won, M.-H. and Kim, D.-H. (2004) Correlates of quality of life after stroke. Journal of the Neurological Sciences, 224, 37-41. doi:10.1016/j.jns.2004.05.018

[18] Kimura, M., Robinson, R.G. and Kosier, J.T. (2000) Treatment of cognitive impairment after poststroke depression: A double-blind treatment trial. Stroke; A Journal of Cerebral Circulation, 31, 1482-1486. doi:10.1161/01.STR.31.7.1482

[19] Sarris, J., Moylan, S., Camfield, D.A., Pase, M.P., Mischoulon, D., Berk, M., Jacka, F.N. and Schweitzer, I. (2012) Complementary medicine, exercise, meditation, diet, and lifestyle modification for anxiety disorders: A review of current evidence. Evidence-Based Complementary and Alternative Medicine: eCAM, 809653.

[20] Smith, J.C. (2013) Effects of emotional exposure on state anxiety after acute exercise. Medicine and Science in 
Sports and Exercise, 45, 372-378. doi:10.1249/MSS.0b013e31826d5ce5

[21] Aidar, F.J., De Oliveira, R.J., Silva, A.J., De Matos, D.G., Mazini Filho, M.L., Hickner, R.C. and Machado Reis, V. (2012) The influence of resistance exercise training on the levels of anxiety in ischemic stroke. Stroke Research and Treatment, 298375.

[22] Aidar, F.J., De Oliveira, R.J., Silva, A.J., De Matos, D.G., Carneiro, A.L., Garrido, N., Hickner, R.C. and Reis, V.M. (2011) The influence of the level of physical activity and human development in the quality of life in survivors of stroke. Health and Quality of Life Outcomes, 9, 89. doi:10.1186/1477-7525-9-89

[23] Skidmore, E.R., Whyte, E.M., Holm, M.B., Becker, J.T., Butters, M.A., Dew, M.A., Munin, M.C. and Lenze, E.J. (2010) Cognitive and affective predictors of rehabilitation participation after stroke. Archives of Physical Medicine and Rehabilitation, 91, 203-207. doi:10.1016/j.apmr.2009.10.026

[24] De Haan, R., Limburg, M., Bossuyt, P., Van der Meulen, J. and Aaronson, N. (1995) The clinical meaning of Rankin "handicap" grades after stroke. Stroke; A Journal of Cerebral Circulation, 26, 2027-2030. doi:10.1161/01.STR.26.11.2027

[25] Brazilian Society of Cerebrovascular Diseases (BSCD) (1999) Working group on cerebrovascular pathology of ABN. Rankin scale of disability changed and modified Barthel index. Newsletter, 6, 7-12.

[26] Beck, A.T., Ward, C.H., Mendelson, M., Mock, J. and Erbaugh, J. (1961) An inventory for measuring depression. Archives of General Psychiatry, 4, 561-571. doi:10.1161/01.STR.26.11.2027

[27] Gorenstein, C. and Andrade, L. (1998) Inventário de depressão de beck: Propriedades psicométricas da versão em português. Revista de Psiquiatria Clínica, Órgão Oficial do Departamento e Instituto de Psiquiatria Faculdade de Medicina-Universidade de São Paulo, 25, 245-250.

[28] Dunn, G., Sham, P. and Hand, D. (1993) Statistics and the nature of depression. Psychological Medicine, 23, 871889. doi:10.1017/S0033291700026350

[29] Gotlib, I.H. (1984) Depression and general psychopathology in university students. Journal of Abnormal Psychology, 93, 19-30. doi:10.1037/0021-843X.93.1.19

[30] Tanaka-Matsumi, J. and Kameoka, V.A. (1986) Reliabilities and concurrent validities of popular self-report measures of depression, anxiety, and social desirability. Journal of Consulting and Clinical Psychology, 54, 328-333. doi:10.1037/0022-006X.54.3.328

[31] Beck, A.T., Steer, R.A. and Carbin, M.G. (1988) Psychometric properties of the beck depression inventory: Twentyfive years of evaluation. Clinical Psychology Review, 8, 77-100. doi:10.1016/0272-7358(88)90050-5

[32] Spielberger, C.D. and Gorsuch, R.L. (1983) Manual for the State-trait anxiety inventory (form Y) ("self-evaluation questionnaire"). Consulting Psychologists Press, Palo Alto.

[33] Biaggio, A. and Natalício, L. (1979) Tradução e adapta- ção do manual de psicologia aplicada IDATE, Rio de Janeiro.

[34] Borg, G.A. (1982) Psychophysical bases of perceived exertion. Medicine and Science in Sports and Exercise, 14, 377-381. doi:10.1249/00005768-198205000-00012

[35] Douglas, V.C., Johnston, C.M., Elkins, J., Sidney, S., Gress, D.R. and Johnston, S.C. (2003) Head computed tomography findings predict short-term stroke risk after transient ischemic attack. Stroke; A Journal of Cerebral Circulation, 34, 2894-2898.

doi:10.1161/01.STR.0000102900.74360.D9

[36] Flossmann, E. and Rothwell, P.M. (2003) Prognosis of vertebrobasilar transient ischaemic attack and minor stroke. Brain: A Journal of Neurology, 126, 1940-1954.

[37] Hardie, K., Hankey, G.J., Jamrozik, K., Broadhurst, R.J. and Anderson, C. (2004) Ten-year risk of first recurrent stroke and disability after first-ever stroke in the Perth community stroke study. Stroke; A Journal of Cerebral Circulation, 35, 731-735.

doi:10.1161/01.STR.0000116183.50167.D9

[38] Hardie, K., Hankey, G.J., Jamrozik, K., Broadhurst, R.J. and Anderson, C. (2003) Ten-year survival after first-ever stroke in the perth community stroke study. Stroke; A Journal of Cerebral Circulation, 34, 1842-1846. doi:10.1161/01.STR.0000082382.42061.EE

[39] Hankey, G.J. (2005) Secondary prevention of recurrent stroke. Stroke; A Journal of Cerebral Circulation, 36, 218221. doi:10.1161/01.STR.0000153048.87248.3b

[40] Streifler, J.Y., Eliasziw, M., Benavente, O.R., Alamowitch, S., Fox, A.J., Hachinski, V.C. and Barnett, H.J.M. (2002) Prognostic importance of leukoaraiosis in patients with symptomatic internal carotid artery stenosis. Stroke; A Journal of Cerebral Circulation, 33, 1651-1655. doi:10.1161/01.STR.0000018010.38749.08

[41] Sachdev, P.S., Brodaty, H., Valenzuela, M.J., Lorentz, L., Looi, J.C.L., Wen, W. and Zagami, A.S. (2004) The neuropsychological profile of vascular cognitive impairment in stroke and TIA patients. Neurology, 62, 912-919. doi:10.1212/01.WNL.0000115108.65264.4B

[42] Hankey, G.J. (2003) Long-term outcome after ischaemic stroke/transient ischaemic attack. Cerebrovascular Diseases (Basel, Switzerland), 16, 14-19. doi: $10.1159 / 000069936$

[43] Simis, S. and Nitrini, R. (2006) Cognitive improvement after treatment of depressive symptoms in the acute phase of stroke. Arquivos De Neuro-Psiquiatria, 64, 412-417. doi:10.1590/S0004-282X2006000300012

[44] Dalle Carbonare, L., Maggi, S., Noale, M., Giannini, S., Rozzini, R., Lo Cascio, V. and Crepaldi, G. (2009) Physical disability and depressive symptomatology in an elderly population: A complex relationship. The Italian Longitudinal Study on Aging (ILSA). The American Journal of Geriatric Psychiatry: Official Journal of the American Association for Geriatric Psychiatry, 17, 144-154. doi:10.1097/JGP.0b013e31818af817

[45] Zatzick, D., Jurkovich, G.J., Rivara, F.P., Wang, J., Fan, M.-Y., Joesch, J. and Mackenzie, E. (2008) A national US study of posttraumatic stress disorder, depression, and work and functional outcomes after hospitalization for 
traumatic injury. Annals of Surgery, 248, 429-437.

[46] Siepman, T.A.M., Janssens, A.C.J.W., De Koning, I., Polman, C.H., Boringa, J.B. and Hintzen, R.Q. (2008) The role of disability and depression in cognitive functioning within 2 years after multiple sclerosis diagnosis. Journal of Neurology, 255, 910-916. doi:10.1007/s00415-008-0814-x

[47] Lee, Y. and Park, K. (2008) Does physical activity moderate the association between depressive symptoms and disability in older adults? International Journal of Geriatric Psychiatry, 23, 249-256. doi:10.1002/gps.1870

[48] Ding, Y., Li, J., Lai, Q., Rafols, J.A., Luan, X., Clark, J. and Diaz, F.G. (2004) Motor balance and coordination training enhances functional outcome in rat with transient middle cerebral artery occlusion. Neuroscience, 123, 667674. doi:10.1016/j.neuroscience.2003.08.031

[49] Carod-Artal, F.J. (2006) Post-stroke depression (I). Epidemiology, diagnostic criteria and risk factors. Revista De Neurologia, 42, 169-175.

[50] Carod-Artal, F.J., Ferreira Coral, L., Trizotto, D.S. and Menezes Moreira, C. (2009) Poststroke depression: Prevalence and determinants in Brazilian stroke patients. Cerebrovascular Diseases (Basel, Switzerland), 28, 157-165. doi: $10.1159 / 000226114$
[51] Sagen, U., Vik, T.G., Moum, T., Mørland, T., Finset, A. and Dammen, T. (2009) Screening for anxiety and depression after stroke: Comparison of the hospital anxiety and depression scale and the Montgomery and Asberg depression rating scale. Journal of Psychosomatic Research, 67, 325-332. doi:10.1016/j.jpsychores.2009.03.007

[52] Cumming, T.B., Collier, J., Thrift, A.G. and Bernhardt, J. (2008) The effect of very early mobilisation after stroke on psychological well-being. Journal of Rehabilitation Medicine: Official Journal of the UEMS European Board of Physical and Rehabilitation Medicine, 40, 609-614. doi:10.2340/16501977-0226

[53] Fure, B. (2007) Depression, anxiety and other emotional symptoms after cerebral stroke. Tidsskrift for Den Norske Lageforening: Tidsskrift for Praktisk Medicin, Ny Rakke, 127, 1387-1389.

[54] Conn, V.S. (2010) Anxiety outcomes after physical activity interventions: Meta-analysis findings. Nursing Research, 59, 224-231. doi:10.1097/NNR.0b013e3181dbb2f8

[55] Subirats Bayego, E., Subirats Vila, G. and Soteras Martínez, I. (2012) Exercise prescription: Indications, dosage and side effects. Medicina Clínica, 138, 18-24. doi:10.1016/j.medcli.2010.12.008 